\title{
Oschlies received the 2011 Georg Wüst Prize
}

\author{
Jörg-Olaf Wolff
}

Received: 2 April 2011 / Accepted: 4 April 2011 /Published online: 27 April 2011

(C) Springer-Verlag 2011

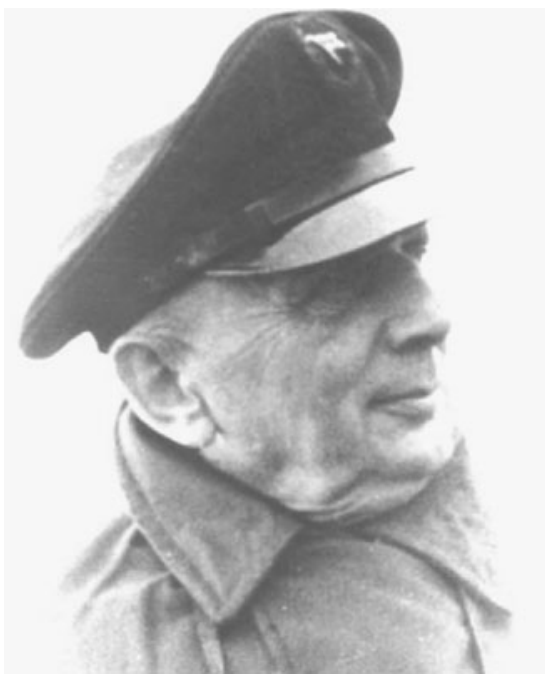

Prof. Dr. Georg Wüst

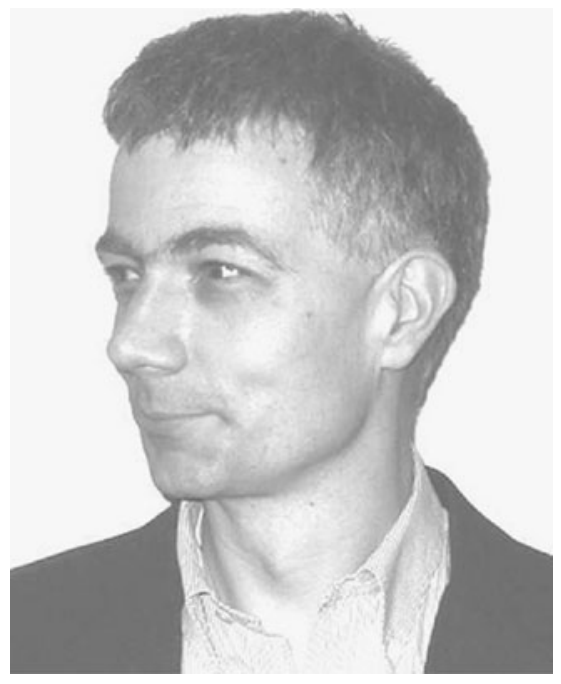

Prof. Dr. Andreas Oschlies
Prof. Dr. Andreas Oschlies received the Georg Wüst Prize 2011 at the European Geophysical Union (EGU) General Assembly in Vienna, Austria, April 2011. This biannual prize is awarded for outstanding contributions to the general field of oceanography and is sponsored by the German Society for Marine Research and Ocean Dynamics. The following is a transcript of the citations by Profs. Zielinski and Wolff, and the response by Prof. Oschlies.

J.-O. Wolff $(\bowtie)$

ICBM, University of Oldenburg,

Oldenburg, Germany

e-mail: wolff@icbm.de

\section{Citation by Prof. Zielinski}

As president of the German Society for Marine Research, I have the honour and distinct pleasure to present the Georg Wüst Prize to Prof. Andreas Oschlies from IFM-GEOMAR, Kiel, Germany. This prize was established as an award for outstanding contributions to oceanic research in marine disciplines. Andreas Oschlies is an outstanding marine scientist, addressing the oceanic carbon uptake and its climate sensitivity by means of physical, biogeochemical and ecological modelling. While looking for the 'big picture', he is carefully investigating the significance and contribution of every single parameter and coefficient. His work builds bridges between field work and simulation, 
between recent observations and future scenarios, and between science and society.

The German Society for Marine Research (Deutsche Gesellschaft für Meeresforschung, DGM) awards this biennial prize with the generous sponsorship of the international Springer Journal Ocean Dynamics.

Specifically, it is meant to honour excellent mid-career scientists, thus targeting a group missed by the 'outstanding life-time achievements' awards or those directed explicitly at bright 'young scientists'. It is the intent that this honour will further inspire the recipient to address the demanding tasks that are imposed in understanding and predicting the oceans response and contribution to climate change.

Congratulations Andreas!

Prof. Dr. Oliver Zielinski, President German Society for Marine Research

\section{Citation by Prof. Wolff}

The inaugural presentation of the Georg Wüst Prize was presented at the 2005 EGU General Assembly in Vienna by Prof. Arnold L. Gordon, Lamont-Doherty Earth Observatory of Columbia University and I to Dr. Stephen Rintoul, CSIRO, Hobart, Australia. Since then, the Georg Wüst Prize has been awarded to Dr. Eberhard Fahrbach in 2007 and Prof. Karen Heywood in 2009.

This year, in 2011, the Georg Wüst Prize is presented to Prof. Andreas Oschlies of the IFM-GEOMAR in Kiel, Germany.

Before discussing the achievements of Andreas Oschlies, I first quote from Arnold's statement at the 2005 presentation concerning Georg Wüst's achievements.

Georg Wüst, born 15 June 1890, brought descriptive oceanography into the modern era. Through a careful analysis of each hard-won observational data point that passed his meticulous quality control procedures, he probed into the secrets of the ocean, contributing to several research areas. He is best known for his Atlantic Ocean studies, where with great insight and skill he combined water mass analysis by means of the temperature-salinity relationship and the core method, with the dynamic approach of geostrophic balance, to reveal the nature of the deep Atlantic's stratification and circulation.

Coming now to Andreas Oschlies, I quote from the nomination letter:

Andreas Oschlies has made seminal contributions to the understanding of physical - biogeochemical interactions based on complex numerical ocean models. This resulted in coupled ecosystem circula- tion models, which are suitable to address the effects of climate change in the ocean and their potential feedback to the climate system. He has shown his capabilities of quickly responding to new scientific ideas and evidence from the field of marine biogeochemistry by implementing them skilfully into high-end ocean models thereby providing major insight into their overall significance. A common trait of all these studies is a critical evaluation of model performance and uncertainty of the results. His contribution to international and national research programmes like e.g. the JGOFS Global synthesis working group and the SCOR GEOTRACES planning group demonstrate effective leadership in his field.

The prize consists of a 3-D laser-engraved picture of the old meteor in a glass block, a prize certificate, a honorary lifetime membership of the German Society of Marine Research and a prize money of $1,500 €$.

Congratulations Andreas!

Prof. Dr. Jörg-Olaf Wolff, Chief Editor Ocean Dynamics

\subsection{Response by Prof. Oschlies}

Last December, Jörg-Olaf Wolff informed me that I should be awarded the Georg Wüst prize. That has made me feel very honoured and is a great motivation for my future work.

Science is done by people and also is about people, a fact which is nicely reflected by naming the prize after a person. Although I have not had the chance to meet Georg Wüst in person, my attempts to become an oceanographer can be traced back to him. Looking around for a new study field during the seemingly endless months of my master thesis in theoretical physics at the Cavendish Laboratory in Cambridge, I had been scanning the university library for books that could inform me about oceanography and geophysical fluid dynamics. One of the books that fell into my hands was of Georg Wüst, and I remember well the colour plates illustrating the spreading of water masses in the Atlantic Ocean and making me think that there was some puzzling dynamics behind these patterns that I would like to understand a little better. A few weeks later, I was lucky enough to have an appointment with Jürgen Willebrand at IFM Kiel, and more luckily, he offered me a PhD studentship in his group at the very institute that Georg Wüst had rebuilt as first director after the World War II.

With his unselfish character and thoughtful and rigorous way to approach scientific problems with full attention to apparent details, Jürgen has been an influential mentor in my career. When I wanted to see Jürgen, I had to pass by the office of Rolf Käse. He impressed me by his great 
motivation and inspiring generation of new ideas and hypotheses. Rolf was also the person who introduced me, a modeller, to sea-going oceanography and who taught me the beauty and value of real data, including Wüst's method of using oxygen to track water masses. During my postdoctoral period, I had the privilege to work with Veronique Garçon. She has taught me a lot about ethics in science and how to keep an upbeat mind when dealing with adverse situations. Different as they are in character, they all have helped me not only by being excellent scientists but also by being great personalities. I am very grateful to them and to many more colleagues all over the world. In the end, science is about sharing interests with people, with papers being a by-product, although some evaluation metrics want to tell us the contrary.

Georg Wüst was an observational oceanographer, and apparently, I am the first modeller being awarded the prize named after him. I will therefore try to convince you that this may still make sense. Having worked for more than 15 years on the coupling of marine ecosystem components with ocean circulation models, I have had many opportunities to experience the limitations and flaws of numerical models. Things go wrong and are not always straightforward. Only by confronting models with real data can we properly assess them. Well, in the spirit of Georg Wüst, we now use biogeochemical tracer data, including oxygen measurements taken on his Meteor expedition 1925-1927, to constrain routinely and improve eventually our models. In this way, our models are merely tools that extend Wüst's original core method and provide a dynamical picture of water mass transport and the role of biological sources and sinks in modifying biogeochemical tracer distributions.

I would like to thank the Deutsche Gesellschaft für Meeresforschung, Springer and Ocean Dynamics for awarding me with the Georg Wüst prize, and Oliver Zielinski and Jörg-Olaf Wolff for their kind citations. The work I have been awarded for is the work of many scientists I have had the pleasure to collaborate with, including all the members of our biogeochemical modelling group at IFM-GEOMAR in Kiel. As many other things in life, science greatly benefits from communication and open exchange. Meetings like this one and societies like the Deutsche Gesellschaft für Meeresforschung play essential roles in bringing people together and letting scientific ideas compete in an open and constructive manner. In our home institutions, we ourselves have the responsibility to do our best to provide the environment that allows scientists and scientific ideas to thrive. Following Georg Wüst, who apparently did this very successfully when he was professor at the University of Kiel from 1946 until his retirement in 1959, I will do my best to promote scientific excellence and academic freedom.

Prof. Dr. Andreas Oschlies, Leibniz-Institut für Meereswissenschaften (IFM-GEOMAR), Kiel, Germany 